\title{
Effect of Acute Tyrosine Depletion in Using a Branched Chain Amino-Acid Mixture on Dopamine Neurotransmission in the Rat Brain
}

\author{
Marisa Le Masurier', Weite Oldenzeil', Claire Lehman', Philip Cowen ${ }^{2}$ and Trevor Sharp*,', \\ 'Department of Pharmacology, Oxford University, Oxford, UK; ${ }^{2}$ University Department of Psychiatry, Warneford Hospital, Oxford, UK
}

\begin{abstract}
Central dopamine function is reduced by decreasing the availability of the catecholamine precursor, tyrosine, using a tyrosine-free amino acid mixture containing multiple large neutral as well as branched chain amino-acids, which compete with tyrosine for uptake into the brain. Current mixtures are cumbersome to make and administer, and unpalatable to patients and volunteers. Here, we investigate whether individual or limited amino-acid combinations could reduce brain tyrosine levels and hence dopamine function. Measurements of regional brain tyrosine levels, catecholamine and indoleamine synthesis (L-DOPA and 5-HTP accumulation, respectively) were used to identify an effective paradigm to test in neurochemical, behavioral and fos immunocytochemical models. Administration of leucine or isoleucine, or a mixture of leucine, isoleucine, and valine reduced tyrosine and 5-HTP, but not L-DOPA accumulation. A mixture of leucine, valine, and isoleucine supplemented with tryptophan reduced brain tyrosine and L-DOPA, but not 5-HTP. In microdialysis experiments this amino-acid mixture reduced basal and amphetamine-evoked striatal dopamine release, as well as amphetamine-induced hyperactivity. This mixture also reduced amphetamine-induced fos expression in striatal areas. In conclusion, the present study identified a small combination of amino acids that reduces brain tyrosine and dopamine function in a manner similar to mixtures of multiple amino acids. This minimal mixture may have use as a dopamine reducing paradigm in patient and volunteer studies.

Neuropsychopharmacology (2006) 31, 310-317. doi:I0. I038/sj.npp. I 300835; published online 20 July 2005
\end{abstract}

Keywords: tyrosine; dopamine; branched chain amino acids; in vivo microdialysis; fos

\section{INTRODUCTION}

Tyrosine depletion induced by amino-acid mixtures lacking the catecholamine precursors, tyrosine, and phenylalanine, reduces dopamine synthesis, as well as the dopaminereleasing and psychostimulant effects of amphetamine in animal models (McTavish et al, 1999b, 2001b). These mixtures have recently been found to reduce the dopamine-mediated immediate early gene response to amphetamine, measured by fos immunocytochemistry, and to attenuate amphetamine-induced raclopride displacement in an animal PET neuroimaging model (Le Masurier et al, $2004 a, b)$. Recent clinical trials have shown that a tyrosinefree amino-acid mixture reduces psychostimulant effects of amphetamine as well as the symptoms of mania in acutely manic patients (McTavish et al, 2001a). Thus, such mixtures appear not only to reduce brain tyrosine and dopamine

* Correspondence: Dr T Sharp, Department of Pharmacology, Oxford University, Mansfield Road, Oxford, OXI 3QT, UK, Tel: + 441865 27|850, Fax: + 44 1865 27|853, E-mail: trevor.sharp@pharm.ox.ac.uk Received 17 August 2004; revised 7 June 2005; accepted 8 June 2005 Online publication: 21 June 2005 at http://www.acnp.org/citations/ Npp06215040373/default.pdf synthesis and release but also to attenuate dopamine function in a variety of models, in both animals and humans. Several studies indicate that the mixtures decrease the function of dopamine but not noradrenaline or 5-HT (McTavish et al, 1999a, b, 2001b).

These mixtures are thought to reduce brain tyrosine via stimulation of peripheral protein synthesis, with the result that plasma tyrosine levels fall (Gessa et al, 1974). In addition however, brain tyrosine may fall due to increased circulating branched chain and large neutral amino acids, which compete with tyrosine at the LAT-1 transporter at the blood-brain barrier (Ellenbogen et al, 1996; Fernstrom, $1983,2000)$. It is unclear which of these mechanisms is most important for the tyrosine-depleting effects of tyrosine-free mixtures, or indeed whether an increase in protein synthesis is necessary over and above competition at the LAT-1 to achieve central tyrosine depletion. In support of the latter mechanism, a number of groups have reported evidence that brain tyrosine can be reduced by administering bolus doses of other large neutral amino acids (Wurtman et al, 1974; Carlsson and Lindqvist, 1978; Tam et al, 1990).

Investigation of the effects of single or small numbers of amino acids on dopamine function would help define the 
relative contributions of an increase in peripheral protein synthesis and competition from other amino acids at LAT-1 in the tyrosine-depleting effects of these dietary manipulations. Another motivation for reducing the number of amino acids administered is that fuller mixtures are cumbersome to make and administer, and unpalatable in patients and volunteers.

This study tested the effect of a single, or small numbers of branched chain amino acids (BCAA) on dopamine function, based on the expectation that these BCAA would lower central tyrosine by competing with tyrosine for entry into the brain, for which they share the same transporter. Measurements of regional tyrosine levels and ex vivo catecholamine and 5-HT synthesis were used to identify a paradigm for further testing in in vivo neurochemical, behavioral, and fos immunocytochemical models.

\section{METHODS}

\section{Animals}

Male, Sprague-Dawley rats weighing 250-300 g (HarlanOlac, Bicester, UK) were used in all experiments. Rats were housed under controlled conditions of temperature $\left(21^{\circ} \mathrm{C}\right)$ and humidity $(50 \%)$, in a $12 \mathrm{~h}$ light $/ 12 \mathrm{~h}$ dark cycle and provided with food (SDS RM3 diet, Lillico, Betchworth, UK) and water ad libitum. Animals were not food deprived before amino-acid injections. All of the experiments were performed in accordance with the UK Home Office Animals (Scientific Procedures) Act 1986. Typically, amino acid treatments were administered in the morning $(1000-1200 \mathrm{~h})$ and animals were killed in the afternoon (1400-1600 h) to avoid systematic diurnal changes in tyrosine levels (eg Voog and Eriksson, 1992).

\section{Amino-Acid Treatments}

The following amino-acid treatments were tested:

(i) leucine $(1 \mathrm{~g} / \mathrm{kg}$ i.p.),

(ii) isoleucine $(1 \mathrm{~g} / \mathrm{kg}$ i.p.)

(iii) a mixture of leucine, isoleucine, and valine (1 g/ $/ \mathrm{kg}$ i.p.)

(iv) a mixture of leucine, isoleucine, and valine (1 g/kg i.p.), supplemented with tryptophan $(0.045 \mathrm{~g} / \mathrm{kg})$.

The amino-acid mixtures were made up as follows:

$273 \mathrm{mg}$ isoleucine, $409 \mathrm{mg}$ leucine, $318 \mathrm{mg}$ valine with or without $40 \mathrm{mg}$ tryptophan were dissolved in $1 \mathrm{ml}$ distilled water ( $\mathrm{pH}$ adjusted to neutral using $\mathrm{NaOH}$ as appropriate), and the mixture was injected i.p. in a volume of $1 \mathrm{ml} / \mathrm{kg}$. In some experiments, the mixture was supplemented with 250 or $750 \mathrm{mg}$ tyrosine. All amino acids were the l-enantiomer, and in methyl ester form (Sigma, UK).

\section{Ex Vivo Measurement of Tyrosine, Catecholamine, and 5-HT Synthesis}

Rats were injected with a single amino acid, small mixtures, or vehicle either once or twice (two injections $1 \mathrm{~h}$ apart), and then killed at either 1.5 or $3.5 \mathrm{~h}$ following the last injection. The DOPA decarboxylase inhibitor NSD 1015 ( $100 \mathrm{mg} / \mathrm{kg}$ i.p.) was injected $30 \mathrm{~min}$ prior to killing. All experiments included a vehicle group to control for diurnal variations in tyrosine levels. Brain regions were dissected on ice according to the following method: (i) frontal cortices (including cingulate, orbital, and frontal regions) were removed using a $2 \mathrm{~mm}$ coronal slice, (ii) the hypothalamus was cut as a $3 \times 3 \times 2 \mathrm{~mm}^{3}$ block from the ventral surface, and (iii) striatum and nucleus accumbens were cut from a $2 \mathrm{~mm}$ coronal slice starting immediately anterior to the optic chiasma. Once dissected, tissues were snap frozen in isopentane on dry ice $\left(-40^{\circ} \mathrm{C}\right)$ and stored immediately at $-70^{\circ} \mathrm{C}$ prior to neurochemical analysis.

Regional brain tissue extracts were analyzed for tyrosine, L-DOPA, and 5-HTP using HPLC with electrochemical detection. On the day of analysis, tissue pieces were weighed before the addition of $1 \mathrm{ml}$ ice cold $0.1 \mathrm{M}$ perchloric acid, disrupted by sonication (10s), and the supernatant was collected after precipitating the tissue pellet by centrifugation $(10 \mathrm{~min}$ at $1500 \mathrm{~g}$ ). Supernatant samples were then kept on ice until analysis. Supernatant samples were separated on a $250 \times 4.6 \mathrm{~mm}^{2}$ Microsorb HPLC column $\left(\mathrm{C}_{18}\right.$ ODS 2, Rainin) with a mobile phase comprising: $12 \%$ (v/v) methanol, $0.1 \mathrm{M} \mathrm{NaH}_{2} \mathrm{PO}_{4}, 0.1 \mathrm{mM}$ EDTA, $2.7 \mathrm{mM}$ octane sulfonic acid ( $\mathrm{pH} 3.8$ ) pumped at $1.2 \mathrm{ml} / \mathrm{min}$. Detection was by a BAS (LC-4B/C) potentiometer with a glassy carbon working electrode set at $+0.8 \mathrm{~V}$. All samples from a given region were analyzed on the same day to control for any day-to-day variation in standard solutions and assay sensitivity.

\section{Microdialysis Measurement of Striatal Extracellular Dopamine}

Rats were anesthetized with choral hydrate $(500 \mathrm{mg} / \mathrm{kg}$ i.p.) and placed in a stereotaxic frame (Kopf) with the incisor bar set at $-3.3 \mathrm{~mm}$. A stable level of anesthesia was maintained throughout the experiment by administering additional doses of choral hydrate as necessary. Body temperature was maintained at $36.0 \pm 0.5^{\circ} \mathrm{C}$ by means of a homeothermic blanket.

A concentric microdialysis probe $(2 \times 0.3 \mathrm{~mm}$ tip, Hospal AN69 membrane) was implanted in the right striatum (coordinates (mm); AP 0.7, ML 3.2, DV 4.8 relative to bregma and dura surface (Paxinos and Watson, 1986)). The dialysis probe was perfused $(2 \mu \mathrm{l} / \mathrm{min})$ with artificial cerebrospinal fluid of the following composition: $140 \mathrm{mM}$ $\mathrm{NaCl}, 3.0 \mathrm{mM} \mathrm{KCl}, 2.5 \mathrm{mM} \mathrm{CaCl}_{2}, 1.0 \mathrm{mM} \mathrm{MgCl} 2,1.2 \mathrm{mM}$ $\mathrm{Na}_{2} \mathrm{HPO}_{4}, 0.27 \mathrm{mM} \mathrm{NaH} \mathrm{PO}_{4}, 7.2 \mathrm{mM}$ glucose. Dialysates (20 min samples) were analyzed for dopamine using HPLC with electrochemical detection (Sharp and Zetterström, 1992). Samples were separated on a $150 \times 4.6 \mathrm{~mm}^{2}$ Dynamax Microsorb column (ODS $2 \mathrm{C}_{18} 5 \mu \mathrm{m}$ particles, Varian) using a mobile phase comprising $16 \%(\mathrm{v} / \mathrm{v})$ methanol, $0.1 \mathrm{mM}$ EDTA, $0.1 \mathrm{M} \mathrm{NaH} \mathrm{PO}_{4}, 0.46 \mathrm{mM}$ octane sulfonic acid, $\mathrm{pH} 3.65(1.0 \mathrm{ml} / \mathrm{min}$ flow rate). Electrochemical detection was by a BAS (LC-4B/C) potentiometer with a glassy carbon working electrode set at $+0.7 \mathrm{~V}$.

Once basal dopamine levels were constant (typically $2 \mathrm{~h}$ after probe implantation), animals received two injections ( $1 \mathrm{~h}$ apart) of the mixture of leucine, isoleucine, valine, and tryptophan (each $1 \mathrm{ml} / \mathrm{kg}$ i.p.) or an equivalent volume of saline. Amphetamine $(2 \mathrm{mg} / \mathrm{kg})$ was administered s.c. $1 \mathrm{~h}$ after the last injection of amino-acid mixture/saline. 


\section{Behavioral Measurements}

Rats were placed individually in Perspex cages, each cage equipped with 15 horizontal photoelectric beams (aimed across the box $2 \mathrm{~cm}$ above the floor) to enable automated monitoring of locomotor activity (Columbus Instruments, Columbia, $\mathrm{OH}$ ). Animals were allowed $2 \mathrm{~h}$ to acclimatize, before being given the amino acid or drug injections. Rats were administered two injections of either the mixture of leucine, isoleucine, valine, and tryptophan, the same mixture supplemented with tyrosine or saline control (separated by $60 \mathrm{~min}$ ) followed $60 \mathrm{~min}$ later by an injection of $2 \mathrm{mg} / \mathrm{kg}$ s.c. amphetamine. Activity recording commenced $5 \mathrm{~min}$ after amphetamine challenge when all animals had been injected and replaced in their cages. Activity counts, measured as the number of times an individual rat interrupted a photoelectric beam, were recorded over the subsequent $1 \mathrm{~h}$ period.

\section{Immunohistochemistry}

Rats were caged singly $1 \mathrm{~h}$ prior to being administered two injections of the mixture of leucine, isoleucine, valine, and tryptophan or saline control (separated by $60 \mathrm{~min}$ ) followed $60 \mathrm{~min}$ later by injection of $2 \mathrm{mg} / \mathrm{kg}$ s.c. amphetamine. Fos immunocytochemistry was carried out as described previously (Le Masurier et al, 2004a). Briefly, $2 \mathrm{~h}$ after the final injection, the rats were deeply anesthetized with phenobarbitone $(200 \mathrm{mg} / \mathrm{kg}$ i.p. $)$ and perfused transcardially with $4 \%$ paraformaldehyde in $0.1 \mathrm{M}$ phosphate buffer ( $\mathrm{pH} 7.4$ ). Brains were removed and postfixed overnight at $4^{\circ} \mathrm{C}$. Vibratome-cut coronal sections $(40 \mu \mathrm{m})$ were incubated for $30 \mathrm{~min}$ in $1 \% \mathrm{H}_{2} \mathrm{O}_{2}$ in immunobuffer $(0.1 \mathrm{M} \mathrm{NaCl}, 5 \mathrm{mM}$ $\mathrm{KCl}, 8 \mathrm{mM} \mathrm{Na} \mathrm{HPO}_{4}, 15 \mathrm{mM} \mathrm{NaH} \mathrm{PO}_{4} 10 \mathrm{mM}$ Tris base, $0.3 \%$ Triton $\mathrm{X}-100$, and $0.04 \%$ Thimerosal), followed by $30 \mathrm{~min}$ incubation in $2 \%$ normal goat serum, and $72 \mathrm{~h}$ incubation with primary fos antibody. The primary antibody was a polyclonal antibody raised against a peptide mapping within a highly conserved domain of $c$-fos p62 of human origin (identical to corresponding rat domain), raised in rabbit (c-fos (K-25): sc-253, Santa Cruz, UK), which broadly reacts with fos-related antigens. Sections were then incubated with secondary antibody (Vector Laboratories, Peterborough, UK) for $2 \mathrm{~h}$. Fos-like immunoreactivity was visualized using a Vectastain $A B C$ elite kit (Vector Lab) and diaminobenzidine $(0.025 \%)$. Sections were dehydrated and defatted and then cover-slipped with Styrolite.

\section{Quantification of fos-Immunoreactivity}

Sections were viewed under a light microscope $(\times 10$ objective) and the number of fos-positive cells was counted automatically using image analysis software (Scion Image 6.32). Images were captured, offset against background signals by thresholding, and then cell counts were made bilaterally from each region of interest (area of $0.09 \mathrm{~mm}^{2}$ ) on two consecutive sections per animal, with the observer blinded to treatment. The areas quantified were selected and identified as described previously (Le Masurier et al, 2004a).

\section{Statistical Analysis}

Measurements of whole tissue levels of tyrosine, L-DOPA, and 5-HTP, and ambulatory counts were analyzed statistically using one-way analysis of variance (ANOVA) followed post hoc by Dunnett's test. The fos-positive cell count data were analyzed on a region-by-region basis using oneway ANOVA followed by post hoc Bonferroni test. The significance level was set at $P<0.05$.

For the microdialysis experiments, absolute levels of dopamine were meaned for each time point ( $n=12$ rats per group). Statistical analysis was based on absolute data. Baseline data were separated from post-amphetamine data, and both data sets were initially subjected to an area under the curve (AUC) analysis. The baseline data were also inspected using a two-way ANOVA as the AUC analysis was not considered sufficiently sensitive to detect the late effects observed.

\section{RESULTS}

\section{Effect of Single and Small Numbers of BCAA on Regional Brain Tyrosine, DOPA, and 5-HTP Levels}

Leucine and isoleucine. Single injections of either leucine or isoleucine ( $1 \mathrm{~g} / \mathrm{kg}$ i.p.) caused a fall in tyrosine levels (35$75 \%$ ) in the frontal cortex, nucleus accumbens and striatum, and hypothalamus. However, compared to vehicle controls, neither amino acid had any effect on catecholamine synthesis as measured by DOPA accumulation. There was, however, a fall in 5-HTP accumulation in the nucleus accumbens (leucine) and striatum (leucine and isoleucine) (see Table 1). Basal tyrosine levels showed some region-toregion variation across experiments but this variation was not consistent between experiments (compare Table 1, Figures 1 and 2).

Leucine, isoleucine, and valine mixture. In each brain region studied a mixture of leucine, isoleucine, and valine ( $1 \mathrm{~g} / \mathrm{kg}$ i.p.) caused tyrosine levels to fall significantly, compared to control animals (one-way ANOVA with Dunnett's post hoc test, $P<0.01$; Figure 1a). This fall $(\sim 40 \%$ at $1.5 \mathrm{~h})$ reversed within $3.5 \mathrm{~h}$ of injection. However, this mixture had no effect on DOPA accumulation in any of the areas examined (Figure 1b) even though 5-HTP fell significantly in the striatum and tended to decrease in other regions (Figure 1c).

Leucine, isoleucine, valine, and tryptophan mixture. Tryptophan $(0.045 \mathrm{mg} / \mathrm{kg}$ i.p.) was added to the mixture of leucine, isoleucine, and valine ( $1 \mathrm{~g} / \mathrm{kg}$ i.p.) in an attempt to reverse the 5-HTP fall. Interestingly, while 5-HTP did not change, DOPA levels decreased in all areas examined. Thus, DOPA accumulation was reduced in the frontal cortex $(-33 \%)$, nucleus accumbens $(-36 \%)$, striatum $(-33 \%)$, and hypothalamus $(-40 \%)$ compared to controls (one-way ANOVA with Dunnett's post hoc test, $P<0.05$, Figure $2 \mathrm{~b}$ ). 5-HTP levels were unaltered in all areas (Figure 2c). In all brain regions studied the mixture of leucine, isoleucine, valine, and tryptophan caused tyrosine levels to fall by $20-$ $40 \%(P<0.05)$ and this effect appeared longer lasting than the mixture without tryptophan (Figure 2a). 

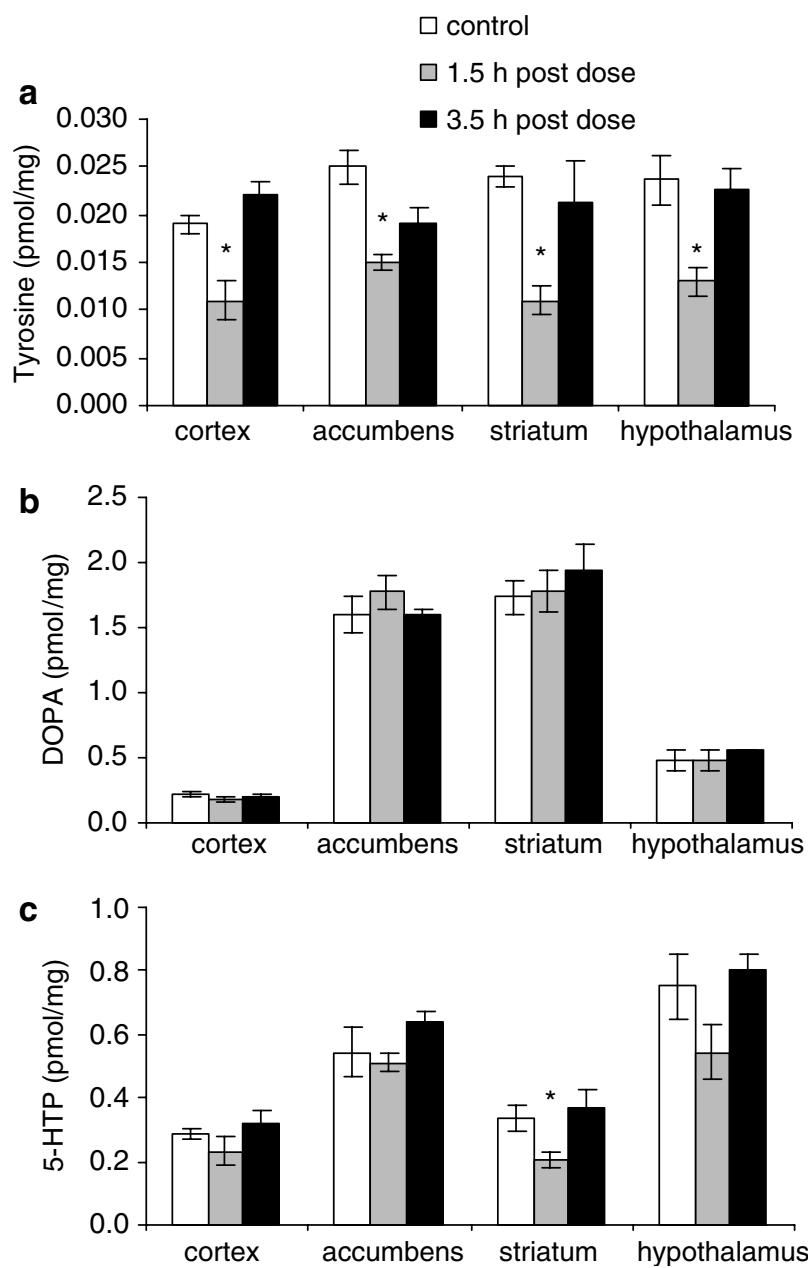

Figure I Time-dependent effect of a mixture of leucine, isoleucine, and valine on regional brain levels of tyrosine (a), DOPA (b), and 5-HTP (c). The mixture or saline was administered as described in the Methods section, in two doses (I g/kg i.p.), I h apart. Rats were killed at 1.5 and $3.5 \mathrm{~h}$ after the final injection. Each column is the mean \pm SEM of three to seven determinations. * $P<0.05$ compared to saline, one-way ANOVA with post hoc Dunnett's test.

\section{Effect of a Mixture of Leucine, Isoleucine, Valine, and Tryptophan on Striatal Extracellular Dopamine Release}

In striatal microdialysates of the anesthetized rat, pretreatment basal dopamine levels were not different between controls $(0.13 \pm 0.052 \mathrm{pmol} / 20 \mathrm{~min}$ sample, $n=12)$ and animals treated with leucine, isoleucine, and valine (plus tryptophan) mixture $(0.13 \pm 0.067 \mathrm{pmol} / 20 \mathrm{~min}$ sample, $n=12$ ). Two injections (60 min apart) of the mixture tended to reduce basal dopamine levels $2 \mathrm{~h}$ following the first injection ( $\sim 40 \%$ decrease), although this effect did not reach statistical significance on an AUC analysis. However, since the decrease was most apparent at the end of the $2 \mathrm{~h}$ postmixture period, we inspected the data using a two-way ANOVA. This analysis revealed a statistically significant treatment $\times$ time interaction $(P<0.05)$ as well as an effect of treatment $(P<0.05)$. Moreover, post hoc analysis using targeted unpaired $t$-tests revealed a significant effect of the BCAA mixture at 100 and 120 min post injection (Figure 3). 

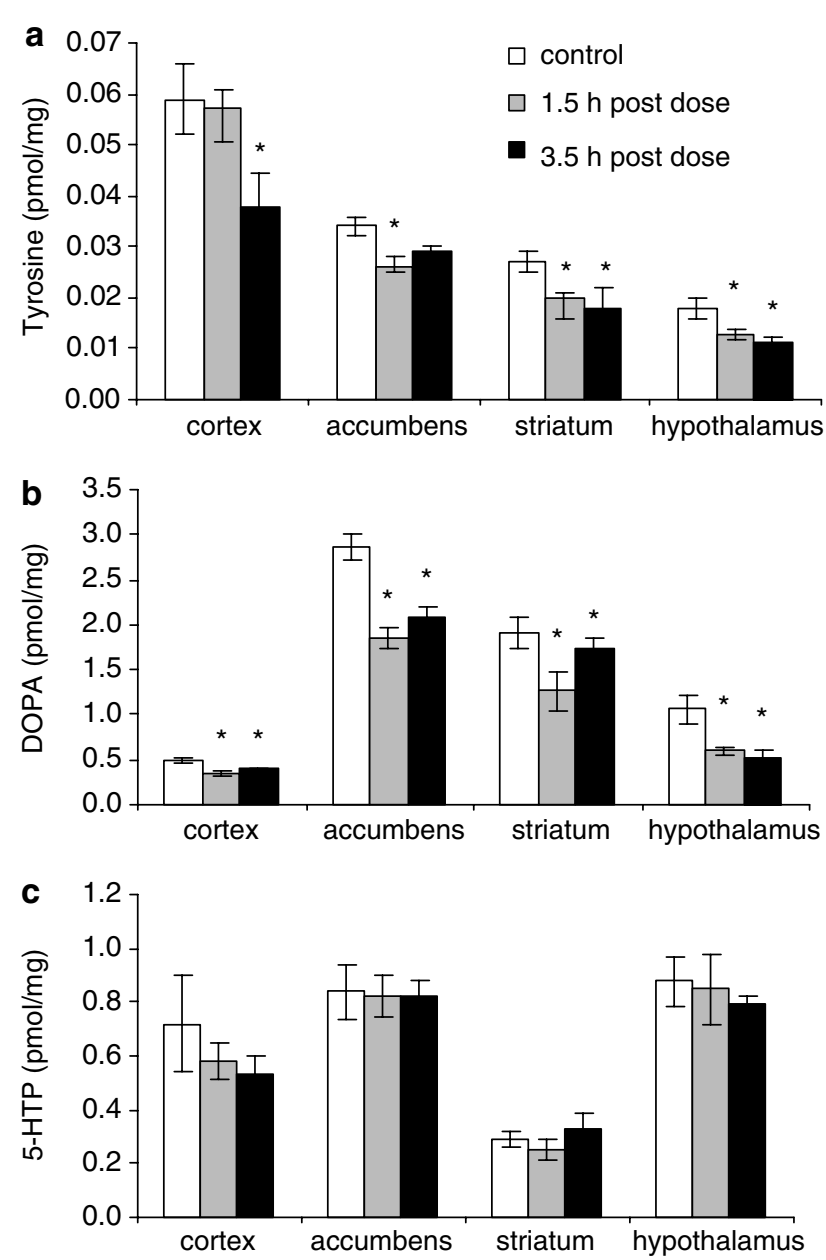

Figure 2 Time-dependent effect of a mixture of leucine, isoleucine, valine, and tryptophan on regional brain levels of tyrosine (a), DOPA (b), and 5-HTP (c). The mixture or saline was administered in two doses $(\mathrm{I} / \mathrm{g} / \mathrm{kg}$ i.p.), I $\mathrm{h}$ apart. Rats were killed at $1.5 \mathrm{~h}$ and $3.5 \mathrm{~h}$ after the final injection. Each column is the mean \pm SEM of three to seven determinations. *P $<0.05$ compared to saline, one-way ANOVA with post hoc Dunnett's test.

In saline-treated animals, $2 \mathrm{mg} / \mathrm{kg}$ s.c. amphetamine caused about a 10 -fold increase in striatal dopamine within 60 min of injection (Figure 3). This response was significantly less $(25 \%)$ in animals administered the mixture (AUC analysis, Student's unpaired $t$-test, $P<0.05)$.

\section{Effect of a Mixture of Leucine, Isoleucine, Valine, and Tryptophan on Amphetamine-Induced Hyperactivity}

Amphetamine (2 mg/kg s.c.) induced an increase in ambulatory activity. This effect was reduced in rats pretreated with the mixture of leucine, isoleucine, and valine (plus tryptophan), compared to saline-treated controls (two-way ANOVA: treatment $\times$ time interaction $P<0.05$; effect of treatment $P<0.001$, Figure 4$)$. The effect of the mixture was reversed (Figure 4) by tyrosine supplementation. Thus, $250 \mathrm{mg} / \mathrm{kg}$ i.p. tyrosine tended to reduce the effect of the mixture at early time points, whereas the effect was completely reversed by $750 \mathrm{mg} / \mathrm{kg}$ i.p. tyrosine (Figure 4). In these experiments, individual behaviors

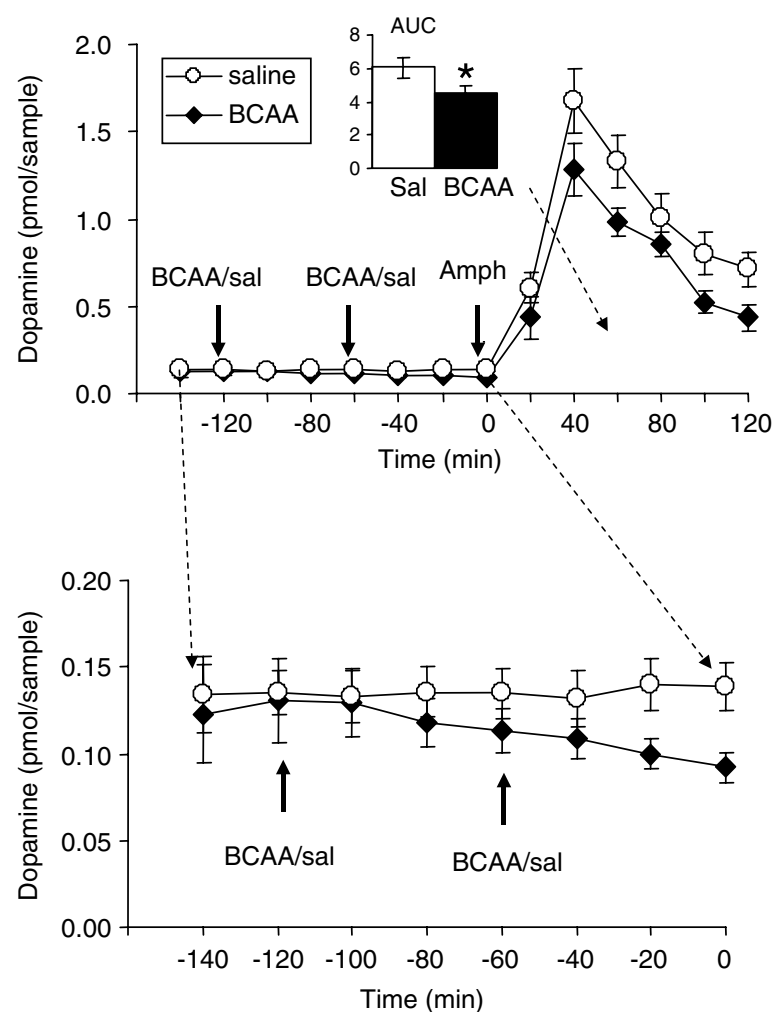

Figure 3 Effect of a mixture of leucine, isoleucine, valine, and tryptophan on baseline and amphetamine-evoked dopamine release in the striatum. The mixture ( $\mid \mathrm{g} / \mathrm{kg}$, i.p.) or saline were given $\mathrm{I}$ and $2 \mathrm{~h}$ prior to amphetamine ( $2 \mathrm{mg} / \mathrm{kg}$ i.p.). Each point represents a mean \pm SEM value $(n=12)$. The inset shows the area under the curve analysis comparing the effect of amphetamine on treatment and control groups (Student's unpaired $t$-test, $* P<0.05$ ).

(locomotion, stereotypies) were also scored using rating scales (McTavish et al, 2001b) but these did not reveal any behaviorally selective effect of the BCAA plus tryptophan mixture (data not shown).

Effect of a Mixture of Leucine, Isoleucine, Valine, and Tryptophan on Amphetamine-Induced fos Expression

Amphetamine $(2 \mathrm{mg} / \mathrm{kg})$ induced a marked increase in fos expression in the striatum and other regions including the frontal cortex compared to saline-injected controls (oneway ANOVA followed by post hoc Bonferroni test, $P<0.05$, Figures 5 and 6). The fos response to amphetamine was attenuated in the medial $(-32 \%)$ and central striatum $(-37 \%)$ and the lateral division of the bed nucleus of the stria terminalis $(-47 \%)$ by prior administration of leucine, isoleucine, and valine (plus tryptophan) mixture compared to saline (one-way ANOVA followed by post hoc Bonferroni test, $P<0.05$, Figures 5 and $6 \mathrm{a})$. In all these regions, this effect of the mixture was partially reversed by injecting $750 \mathrm{mg} / \mathrm{kg}$ i.p. tyrosine (one-way ANOVA followed by post hoc Bonferroni test; Figures 5 and 6). The mixture had no significant effect on amphetamine-induced fos expression in the anterior insular cortices, frontal cortex, claustrum, and lateral habenula (Figure 6). 

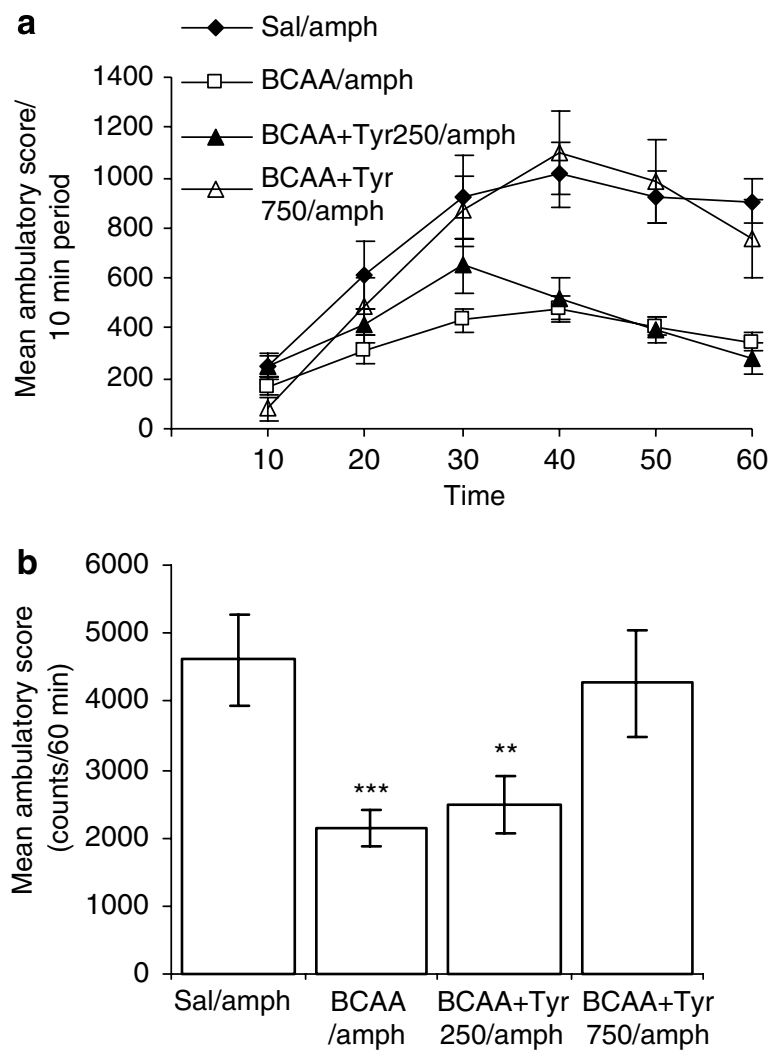

Figure 4 Effect of a mixture of leucine, isoleucine, valine, and tryptophan, and the same mixture supplemented with tyrosine (250 and $750 \mathrm{mg} / \mathrm{kg}$ i.p.), on amphetamine-induced hyperlocomotion in rats. Automated activity counts (a: counts/10 min, b: counts accumulated over $60 \mathrm{~min}$ ) were recorded after mixtures (I g/ $\mathrm{kg}$ i.p.) or saline were given I and $2 \mathrm{~h}$ prior to amphetamine $(2 \mathrm{mg} / \mathrm{kg}$, i.p.). Each point represents a mean \pm SEM value $(n=6)$. (a) two-way ANOVA, time $\times$ treatment interaction $P<0.00 \mathrm{l}$, effect of treatment $P<0.00$ I. (b) $* * * *<<0.00$ I, *** $P<0.0$ I compared to sal/amph, one-way ANOVA with Dunnett's test.

\section{DISCUSSION}

This study builds on previous evidence showing that it is possible to reduce brain tyrosine and dopamine function by administering amino-acid mixtures free of tyrosine. Previous studies have used mixtures of 2-12 amino acids (Biggio et al, 1976; Fernstrom and Fernstrom 1995; McTavish et al, 1999b). Here, single or small numbers of BCAAs were used with the expectation that they would lower brain tyrosine by simple competition at the LAT-1 transporter. The results in fact show that while single, or up to three BCAAs lowered tyrosine, they had no effect on dopamine synthesis in our experiments. It was found, however, that a combination of leucine, isoleucine, valine, and tryptophan reduced dopamine synthesis, release, and function in a variety of models.

Other authors have highlighted that a high plasma level of one large neutral amino acid can prevent those with which it competes entering the brain. Thus, in phenylketonuria, where patients lack the enzyme phenylalanine hydroxylase, the high level of circulating phenylalanine results in disproportionately high brain levels of this amino acid compared to its competitors (Binek-Singer and Johnson 1982; Knudsen et al, 1995; Zielke et al, 2002). More relevant

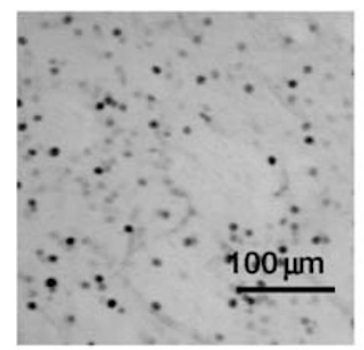

$\mathrm{Sal} / \mathrm{amph}$

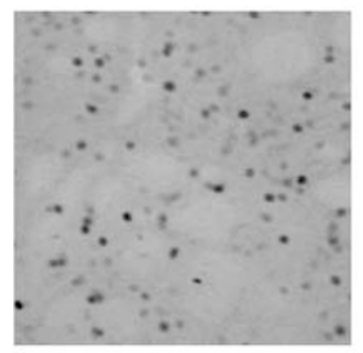

BCAA/amph
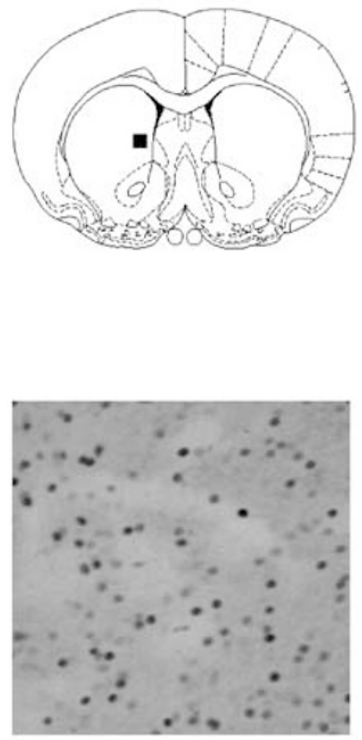

BCAA+Tyr/amph
Figure 5 Bright-field micrographs showing the effect of amphetamine ( $2 \mathrm{mg} / \mathrm{kg}$ s.c.) and a mixture of leucine, isoleucine, valine, and tryptophan ( $\mathrm{g} / \mathrm{kg}$ injected twice, I h apart) on fos immunoreactive cells in the medial striatum (diagram copied from Paxinos and Watson, 1986). Groups are sal/amph (saline followed by amphetamine); BCAA/amph (the mixture followed by amphetamine); BCAA + Tyr/amph (the mixture supplemented with tyrosine followed by amphetamine).
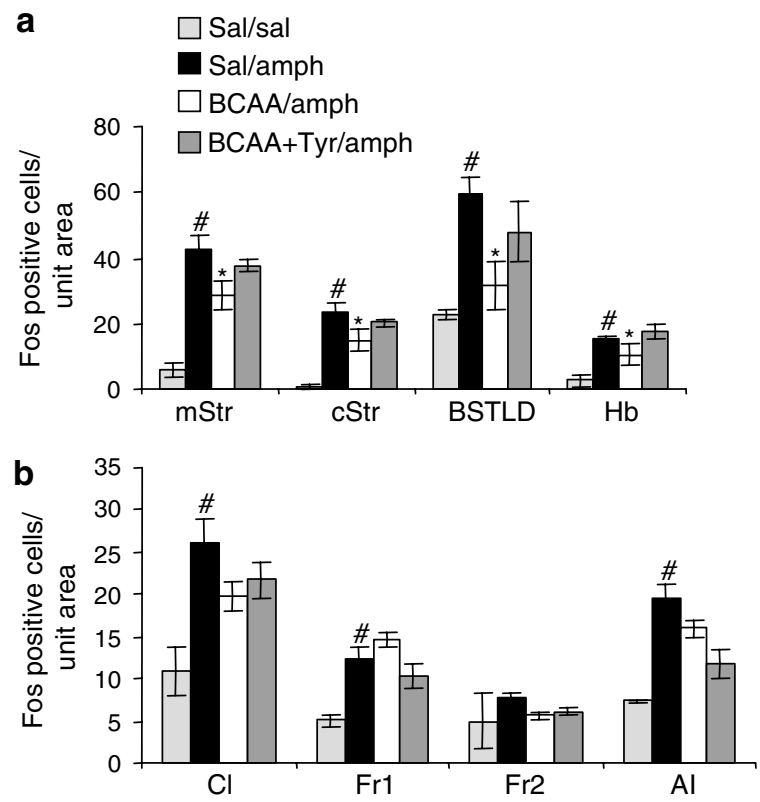

Figure 6 Effect of a mixture of leucine, isoleucine, valine, and tryptophan, and the same mixture supplemented with tyrosine, on amphetamineinduced fos immunoreactivity. The mixtures (I g/kg i.p.) or saline were given $\mathrm{I}$ and $2 \mathrm{~h}$ prior to amphetamine ( $2 \mathrm{mg} / \mathrm{kg}$ s.c). Each bar represents the mean \pm SEM number of fos-positive cells in a $0.09 \mathrm{~mm}^{2}$ area of tissue $(n=6)$. (a) Areas where there was a significant effect of the amino-acid mixture: medial striatum (mStr), central striatum (cStr), basolateral division of bed nucleus of stria terminalis (BSTLD) and lateral habenula ( $\mathrm{Hb}$ ). (b) Areas where there was no significant effect of the amino-acid mixture: claustrum (Cl), frontal cortex area 2 (Fr2), frontal cortex area I (Frl), and anterior insular cortex (Al). ${ }^{*} P<0.05$ compared to sal/amph; ${ }^{\#} P<0.05$ compared to sal/sal (one-way ANOVA with Bonferroni's post hoc test). 
to the present work, previous animal studies have reported evidence that individual BCAAs including leucine, isoleucine, and valine decreased both brain tyrosine levels and catecholamine synthesis (Wurtman et al, 1974; Carlsson and Lindqvist, 1978; Tam et al, 1990). However, in our study, injections of leucine and isoleucine, or leucine, isoleucine, and valine did not reduce L-DOPA accumulation despite reducing central tyrosine by up to $75 \%$. This suggests that the reduction in tyrosine (presumably due to competition at LAT1 but possibly including a contribution from metabolism) was not sufficient to reduce catecholamine synthesis in our hands. The reason for our lack of success in detecting significant effects of individual BCCAs is not certain but we cannot exclude various factors including species differences, prior nutritional status of the animals, or varying levels of handling stress between different laboratories.

Addition of a small amount of tryptophan to the three BCAAs did, however, cause a fall in both tyrosine and L-DOPA accumulation. Surprisingly, the magnitude of the fall in tyrosine after the tryptophan-supplemented BCAA mixture was not greater than the same mixture without tryptophan, although it was longer lasting. The reason for the longer lasting fall in brain tyrosine is not clear but a decrease in plasma tyrosine through activated protein synthesis might play a role. It is possible that the longer lasting fall in tyrosine in the presence of tryptophan contributes to the decrease in catecholamine synthesis. It is also possible that the decrease in catecholamine synthesis in the presence of tryptophan is linked to the lack of decrease in 5-HT synthesis, through a 5-HT-catecholamine interaction. For example, recent studies have shown that 5 $\mathrm{HT}_{2}$ receptor antagonists increase DA cell firing and release (eg see De Deurwaerdere et al, 2004 and references therein). However, against this hypothesis, the effects of the BCAA mixture on 5-HT synthesis were greatest in the striatum, yet all regions tested showed the clear decrease in catecholamine synthesis.

On the basis of finding that the tryptophan-supplemented BCAA mixture reduced catecholamine synthesis across a number of regions, the mixture was further tested in a number of models of dopamine function.

In vivo microdialysis measurements of striatal dopamine release in anesthetized rats showed that the tryptophansupplemented BCAA mixture reduced basal dopamine levels by the order of about $40 \%$, and also caused about a $25 \%$ reduction in amphetamine-evoked dopamine release. This reduction was not as great as seen with the seven amino-acid mixture, which under similar conditions reduced the amphetamine-evoked dopamine release by about $70 \%$ (McTavish et al, 1999b). It is likely that the smaller effect of the tryptophan-supplemented BCAA mixture was due to a smaller decrease in tyrosine and dopamine synthesis, compared to the larger mixture. In other words, the pool of newly synthesized dopamine that is released by amphetamine (Zetterström et al, 1986) was reduced less by the tryptophan-supplemented BCAA mixture than the full mixture. A decrease in availability of newly synthesized DA might also explain at least in part the fall in basal DA output since it is well established that DA synthesis inhibitors have a similar effect.

In keeping with the neurochemical data, the tryptophansupplemented BCAA mixture reduced amphetamine- induced fos expression in the striatum where the effect is mediated by dopamine (Graybiel et al, 1990). This effect was likely due to the decrease in tyrosine availability as it was attenuated when the mixture was supplemented with tyrosine (see also below). The seven amino-acid mixture also reduced amphetamine-induced fos expression in a tyrosine-reversible way (Le Masurier et al, 2004a). As with the dialysis data, the BCAA mixture caused less of a reduction in amphetamine-induced fos expression compared to the full mixture (eg 30 vs $60 \%$ reduction in amphetamine-induced fos expression in the medial striatum). Therefore, both the neurochemical and immunocytochemical data suggest that the tryptophan-supplemented BCAA mixture is less effective at reducing dopamine function than the mixture containing seven amino acids.

Neither the tryptophan-supplemented BCAA mixture (this study), nor the full mixture (Le Masurier et al, 2004a) reduced amphetamine-evoked fos expression in cortical areas. Evidence suggests that the fos response in cortex is mediated by noradrenaline (Bing et al, 1992). Previous results show that the full mixture does reduce amphetamine-evoked dopamine but not noradrenaline release (McTavish et al, 1999a, b). The present data suggest that the tryptophan-supplemented BCAA mixture may also be dopamine selective.

In the behavioral experiments, the tryptophan-supplemented BCAA mixture significantly reduced amphetamineinduced hyper-locomotion, as has been previously observed using the mixture containing seven amino acids (McTavish et al, 2001b). Although the effect of the BCCA mixture in the behavioral model was the greatest of all the models tested, the effect was reversed by adding tyrosine, suggesting that it was due to tyrosine depletion. It should be pointed out, however, that the dose of tyrosine required to reverse the behavioral effects of the BCCA mixture was high $(750 \mathrm{mg} /$ $\mathrm{kg}$ ), and from our previous studies we would expect this dose to induce substantial increases in brain tyrosine (McTavish et al, 1999b). Nevertheless, it is theoretically possible that these increases have less than expected impact on catecholamine synthesis because of enhanced tyrosine metabolism via other routes or poor tyrosine entry into the catecholamine neurons. Lower doses of tyrosine $(100 \mathrm{mg} /$ $\mathrm{kg}$ ) were sufficient to reverse the effects of tyrosine depletions in other studies (Jaskiw and Bongiovanni, 2004) but this involved a model in which the activity of tyrosine hydroxylase was activated, and thereby more sensitive to substrate availability.

Overall, the tryptophan-supplemented BCAA mixture tested in the present study reduces dopaminergic neurotransmission in a variety of rat models. It was apparent, however, that the effect of this mixture in these models was not as great as a mixture containing seven essential amino acids (Le Masurier et al, 2004a, b; McTavish et al, 1999b). This is consistent with a study by Gessa et al (1974), which found that a tryptophan-free amino acid mixture containing a number of essential amino acids was more effective at reducing brain $5-\mathrm{HT}$ synthesis than a mixture containing only six amino acids, which compete at the LAT1 transporter. In contrast, Carlsson and Lindqvist (1978) found that catecholamine synthesis dropped with increasing competition from single large neutral amino acids, therefore predicting a large fall in dopamine neurotransmission. The 
present findings suggest that both a reduction in plasma tyrosine, and competition between amino acids at the LAT1 transporter may be important in mediating the effects of tyrosine-free amino acid mixtures.

Recent studies have tested BCAA mixtures in humans and yielded promising results. A mixture containing leucine, isoleucine, and valine reduced tardive dyskinesia symptoms in patients with schizophrenia (Richardson et al, 1999), decreased plasma tyrosine/BCAA ratios, plasma prolactin (reflecting reduced brain dopamine), and increased task latency in spatial recognition memory tests (Gijsman et al, 2002; Scarna et al, 2002). Such a mixture also reduced manic symptoms when given acutely to manic in-patients (Scarna et al, 2003). The mixture was also well tolerated (better than the mixture containing seven essential amino acids). The present data suggest that addition of tryptophan to the BCAA would have a greater effect on dopamine and at the same time limit reductions in 5-HT.

\section{REFERENCES}

Biggio G, Porceddu ML, Gessa GL (1976). Decrease of homovanillic, dihydroxyphenylacetic acid and cyclic-adenosine- $3^{\prime}, 5^{\prime}$ monophosphate content in the rat caudate nucleus induced by the acute administration of an aminoacid mixture lacking tyrosine and phenylalanine. J Neurochem 26: 1253-1255.

Binek-Singer P, Johnson TC (1982). The effects of chronic hyperphenylalaninaemia on mouse brain protein synthesis can be prevented by other amino acids. Biochem J 206: 407-414.

Bing G, Stone EA, Zhang Y, Filer D (1992). Immunohistochemical studies of noradrenergic-induced expression of $\mathrm{c}$-fos in the rat CNS. Brain Res 592: 57-62.

Carlsson A, Lindqvist M (1978). Dependence of 5-HT and catecholamine synthesis on concentrations of precursor amino-acids in rat brain. Naunyn-Schmiedeberg's Arch Pharmacol 303: $157-164$.

De Deurwaerdere P, Navailles S, Berg KA, Clarke WP, Spampinato $\mathrm{U}$ (2004). Constitutive activity of the serotonin2C receptor inhibits in vivo dopamine release in the rat striatum and nucleus accumbens. J Neurosci 24: 3235-3241.

Ellenbogen M, Young S, Dean P, Palmour R, Benkelfat C (1996). Mood response to acute tryptophan depletion in healthy volunteers: sex differences and temporal stability. Neuropsychopharmacology 15: 465-474.

Fernstrom J (1983). Role of precursor availability in control of monoamine biosynthesis in brain. Physiol Rev 63: 484-546.

Fernstrom J (2000). Can nutrient supplements modify brain function? Am J Clin Nutr 71: 1669S-1675S.

Fernstrom M, Fernstrom J (1995). Acute tyrosine depletion reduces tyrosine hydroxylation rate in rat central nervous system. Life Sci 57: PL97-PL102.

Gessa GL, Biggio G, Fadda F, Corsini GU, Tagliamonte A (1974). Effect of the oral administration of tryptophan-free amino acid mixtures on serum tryptophan, brain tryptophan and serotonin metabolism. J Neurochem 22: 869-870.

Gijsman HJ, Scarna A, Harmer CJ, McTavish SB, Odontiadis J, Cowen PJ et al (2002). A dose-finding study on the effects of branch chain amino acids on surrogate markers of brain dopamine function. Psychopharmacology (Berlin) 160: 192-197.

Graybiel AM, Moratalla R, Robertson HA (1990). Amphetamine and cocaine induce drug-specific activation of the $c$-fos gene in striosome-matrix compartments and limbic subdivisions of the striatum. Proc Natl Acad Sci 87: 6912-6916.
Jaskiw GE, Bongiovanni R (2004). Brain tyrosine depletion attenuates haloperidol-induced striatal dopamine release in vivo and augments haloperidol-induced cataleosy in the rat. Psychopharmacology 172: 100-107.

Knudsen GM, Hasselbalch S, Toft PB, Christensen E, Paulson OB, Lou H (1995). Blood-brain barrier transport of amino acids in healthy controls and in patients with phenylketonuria. J Inherit Metab Dis 18: 653-664.

Le Masurier M, Cowen P, Sharp T (2004a). Fos immunocytochemical studies on the neuroanatomical sites of action of acute tyrosine depletion in the rat brain. Psychopharmacology (Berlin) 171: 435-440.

Le Masurier M, Houston G, Cowen P, Grasby P, Sharp T, Hume S (2004b). Tyrosine-free amino acid mixture attenuates amphetamine-induced displacement of $\left[{ }^{11} \mathrm{C}\right]$ raclopride in striatum in vivo: a rat PET study. Synapse 51: 151-157.

McTavish S, Callado L, Cowen PJ, Sharp T (1999a). Comparison of the effects of alpha-methyl- $p$-tyrosine and a tyrosine-free amino acid load on extracellular noradrenaline in the rat hippocampus in vivo. J Psychopharmacol 13: 379-384.

McTavish S, Cowen P, Sharp T (1999b). Effect of a tyrosine-free amino acid mixture on regional brain catecholamine synthesis and release. Psychopharmacology 141: 182-188.

McTavish SF, McPherson MH, Harmer CJ, Clark L, Sharp T, Goodwin GM et al (2001a). Antidopaminergic effects of dietary tyrosine depletion in healthy subjects and patients with manic illness. Br J Psychiatry 179: 356-360.

McTavish SF, Raumann B, Cowen PJ, Sharp T (2001b). Tyrosine depletion attenuates the behavioural stimulant effects of amphetamine and cocaine in rats. Eur J Pharmacol 424: 115-119.

Paxinos G, Watson C (1986). The Rat Brain in Stereotaxic Coordinates, 2nd edn. Academic Press: New York.

Richardson MA, Bevans ML, Weber JB, Gonzalez JJ, Flynn CJ, Amira L et al (1999). Branched chain amino acids decrease tardive dyskinesia symptoms. Psychopharmacology (Berlin) 143: 358-364.

Scarna A, Gijsman HJ, Harmer CJ, Goodwin GM, Cowen PJ (2002). Effect of branch chain amino acids supplemented with tryptophan on tyrosine availability and plasma prolactin. Psychopharmacology (Berlin) 159: 222-223.

Scarna A, Gijsman HJ, McTavish SF, Harmer CJ, Cowen PJ, Goodwin GM (2003). Effects of a branched-chain amino acid drink in mania. Br J Psychiatry 182: 210-213.

Sharp T, Zetterström $\mathrm{T}$ (1992). In vivo measurement of monoamine neurotransmitter release and metabolism using brain microdialysis. In: Stamford JA (ed). Monitoring Neuronal Activity: A Practical Approach. Oxford University Press: Oxford. pp 147-179.

Tam SY, Elsworth JD, Bradberry CW, Roth RH (1990). Mesocortical dopamine neurons: high basal firing frequency predicts tyrosine dependence of dopamine synthesis. J Neural Transm 81: 97-110.

Voog L, Eriksson T (1992). Diumal rhythms in rat brain large neutral amino acids (LNAAs), monoamines and monoamine metabolites. J Neural Transm 87: 215-224.

Wurtman RJ, Larin F, Mostafapour S, Fernstrom JD (1974). Brain catechol synthesis: control by train tyrosine concentration. Science 185: 183-184.

Zetterström T, Sharp T, Ungerstedt U (1986). Further evaluation of the mechanism by which amphetamine reduces striatal dopamine metabolism: a brain dialysis study. Eur J Pharmacol 132: 1-9.

Zielke HR, Zielke CL, Baab PJ, Collins RM (2002). Large neutral amino acids auto exchange when infused by microdialysis into the rat brain: implication for maple syrup urine disease and phenylketonuria. Neurochem Int 40: 347-354. 